\title{
A New Approach for Liquid Scanners to Determine Flammable Liquid Concentration in Solutions
}

\author{
Ebru Efeoğlu1 (iD) Gürkan Tuna ${ }^{2}$ (D) \\ ${ }^{1}$ Kutahya Dumlupinar University, Department of Software Engineering, Kutahya, Turkey \\ ${ }^{2}$ Trakya University, Department of Computer Programming, Edirne, Turkey
}

A B S TRACT

trong liquid explosives were obtained by mixing some chemical liquids and these ex-
plosives were used in many terrorist attacks in crowded places such as airports, railway stations and shopping malls. They were also used to cause sabotage to facilities that produce, store or use hazardous chemicals in their processes. For this reason, it is very important to take the necessary measures to prevent sabotage and terrorist attacks that may occur in such places in order to ensure public and environmental safety. In this study, a machine learning based liquid control system that can be used in airports, railway stations and shopping malls as well as in places with high fire probability is proposed. The difference of the proposed system from traditional liquid scanner systems is that it can detect the hazardous liquid concentration in the solutions as well as the detection of pure flammable liquids. Linear Discriminant Analysis and Quadratic Discriminant Analysis are used as classifiers and the performances of these techniques are compared. The results show that Quadratic Discriminant Analysis offers higher accuracy and lower error rates compared to Linear Discriminant Analysis.

Keywords:

Security; Liquid classification; Scattering parameter; Linear discriminant analysis; Quadratic discriminant analysis; Accuracy; Performance metrics

\section{INTRODUCTION}

Fire pools can be formed by mixing hazardous chemical liquids; on the other hand, mixing incompatible chemicals can cause exothermic oxidation [1]. Fires involving self-incineration may accelerate depending on the nature of the first spilled liquid and its proximity to the surrounding material. Hazardous chemical reactivity events have been conducted and lessons learned from these cases as presented in [2]. In most cases, oxidisers have caused these fires to start or have contributed to the increasing coverage of the fires [3]. The mixing of incompatible liquids during the use of chemical liquids found in small containers with open covers showed that accidents and fires occurred as a result of accidental spillage and contamination [4]. Therefore, classification of liquids plays an important role in ensuring fire safety [5]. Considering this, fire and explosion hazards of some flammable liquid mixtures were estimated [6] .

Most of the deaths in fires are caused by the inhalation of toxic gases produced during combustion, since it creates a complex toxic environment that includes fire, flame, heat, oxygen depletion, smoke and toxic gases [7].
Researchers have provided methods for assessing life safety hazards in fires and understanding the effects of smoke, heat and toxic fire wastes on humans [8]. The use of machine learning techniques for process safety has been heavily investigated. For example, by considering aerosolisation liquid flammability levels were predicted using machine learning techniques [9]. Performance estimation of suspension freezing crystallization was made for the treatment of hazardous liquid wastes with machine learning methods [10]. In addition, machine learning was used to predict flammability leading properties for liquid aerosol safety [11], to predict hazardous properties of chemical mixtures [12], to set a hazard index for logistics warehouses [13]. Classification of diesel and biodiesel mixtures was carried out using the electronic nose and Linear Discriminant Analysis (LDA) and Quadratic Discriminant Analysis (QDA) techniques [14]. A combustion risk index was developed for flammable liquids based on unsupervised clustering algorithms [15]. Microwave measurement method is fast and is not sensitive to environmental conditions [16] and it is generally used to determine the relative perme- 
ability values of liquids. Microwave measurement methods were used to measure the permeability of thin-layer materials [17] and to measure parameters of silicon [18]. Although there are many microwave measurement methods, the most frequently used one is the open-ended coaxial probe (OECP) method. In this method, liquid measurement is carried out by immersing a probe in the liquid. The complex permeability of glucose / water and water / fluoride solutions was estimated using OECP and artificial neural networks [19],[20].

In the past, X-ray safety systems were used for the detection of hazardous liquids [21] and low energy X-ray transmission technique was one of the techniques employed for this purpose [22]. As well as the low energy X-ray transmission technique, spectral droplet analysis was used for the same purpose [23] . However, since these methods cannot accurately detect some flammable liquids, in other words, the false alarm rate is high, two-stage control consisting of the combination of electronic nasal odour recognition technology and x-ray method has been proposed [24]. In this study, unlike the literature, a liquid identification system with high accuracy, fast and cheaper than other systems is proposed. This proposed system is capable of detecting even a mixture containing $10 \%$ hazardous liquid. Also, thanks to this system, unlike other systems, the hazardous liquid concentration in the mixtures can be determined. The measurement system presented in the study can analyse the liquid remotely without any intervention to the liquid and without opening the lid of the bottle / container filled with liquid, as well as measuring by immersion in the liquid.

\section{MATERIALS AND METHODS}

\section{Discriminant Analysis Methods}

In the following subsections LDA and QDA are reviewed LDA

LDA is a simple and useful classification technique that gives good results in solving complex problems. It performs the separation of classes by searching for the linear combination of variables. The discriminant function is the weighted average of the values of the independent variables. These weights are chosen to divide observations into groups. The discriminant function (L) is given in Eq. (1).

$L=a_{1} x_{1}+a_{2} x_{2}+\ldots+a_{n} x_{n}$

In (1), $x_{1}, x_{2} \ldots \ldots x_{n}$ represent the variables and $a_{1}, a_{2} \ldots \ldots a_{n}$ represent the weights, model coefficients. The weights are calculated using (2).

$a=c^{(-1)}\left(b_{1}-b_{2}\right)$

where c represents covariance matrix, $b_{1}$ and $b_{2}$ are
The discriminant function is obtained from previously known units of group membership, and then this function is used to determine which group will be assigned to new units with unknown group membership. Using a score function defined by the algorithm, linear coefficients that give the highest values in the function are found (3). The aggregated covariance matrix is given in (4).

$$
\begin{aligned}
& S(a)=\frac{a^{T} b_{1}-a^{T} b_{2}}{a^{T} c a} \\
& c=\frac{1}{n_{1}+n_{1}}\left(n_{1} c_{1}+n_{2} c_{2}\right)
\end{aligned}
$$

The Mahalanobis distance is used to determine the best discriminate. The probability that the algorithm has classified correctly determines the value of this distance. A value less than 3 means that the probability of correct classification is high. The Mahalanobis distance between the two groups is given in (5).

$$
d^{2}=a^{T}\left(b_{1}-b_{2}\right)
$$

In order to end the classification process, the condition given in (6) must be met.

$$
a^{T}\left(x\left(\frac{b_{1}+b_{2}}{2}\right)\right)>\log \left(\frac{P\left(c_{1}\right)}{P\left(c_{2}\right)}\right)
$$

Here p shows class probabilities.

\section{QDA}

QDA has quadratic decision limits. Using it, data can be classified into two or more class datasets. It is generally used when the data show normal distribution and the variance-covariance matrices between groups are different. While applying this technique, it should be taken into consideration that the number of observations in each group should be more than the number of variables. The difference of QDA from LDA is that it estimates the covariance matrix for each class. The function specified in (7) is used.

$$
L_{k}(x)=-\frac{1}{2}\left(x-b_{k}\right)^{T} c_{k}^{-1}\left(x-b_{k}\right)-\frac{1}{2} \ln \left|c_{k}\right|+\ln P\left(c_{k}\right)
$$

where $c_{k}$ is the covariance matrix for class $\mathrm{k}, c_{k}^{-1}$ is the inverse of the covariance matrix, and $\left|c_{k}\right|$ is the determinant of the covariance matrix, $P\left(c_{k}\right)$ is the previous probability of class $\mathrm{k}$. Here, the aim is to find the class with the highest $\mathrm{L}$ value.

mean vectors. 


\section{Experimental Setup and Methodology}

The schematic representation of the single-port measurement system with the test setup is shown in Fig. 1. The arrangement consists of a $10 \mathrm{~cm} \times 10 \mathrm{~cm}$ square-shaped antenna, vector network analyser (VNA) and $50 \mathrm{Ohm}$ SubMiniature version A (SMA) coaxial cable to feed the system. Electromagnetic waves are transmitted by the transmitting antenna and reflected signals are collected after the electromagnetic radiation interacts with the liquid. These signals collected by a single-port measuring system are called scattering parameters (S11-parameter). The antenna patch was designed to be $55 \mathrm{~mm}$ in diameter and the antenna resonant frequency is calculated using (8) and (9). The design of the antenna was constructed on a FR4 based dielectric substrate with $1.6 \mathrm{~mm}$ height, 4.4 relative permittivity.

$$
F=\frac{8,791 \times 10^{9}}{f_{r} \sqrt{\varepsilon_{r}}}
$$

$$
a=\frac{F}{\left\{1+\frac{2 h}{\pi \varepsilon_{r} F\left[\ln \left(\frac{\pi F}{2 h}\right)+1,7726\right]^{1 / 2}}\right\}}
$$

where $\varepsilon_{r}$ is relative permittivity of the substrate, $f_{r}$ is the resonant frequency, $\mathrm{h}$ is the height of the substrate, $\mathrm{a}$ is the radius of the patch.

The implementation of this method is easy and fast. Since there is an air gap between the measured liquid and the antenna, measurements should be performed by keeping the antenna as close as possible to the liquid container in order to make more accurate measurements. Liquid measurements can be carried out in closed containers, without opening the lid, non-destructively and by approaching the container filled with liquid 4-5mm. In the study, measurements were made between $1-3 \mathrm{GHz}$ and the S-parameter of each liquid in this frequency band was measured. The measurements were made at room temperature and in the same type of containers. Antenna-liquid distance was $5 \mathrm{~mm}$.

Flammable liquids should not be stored in the same place

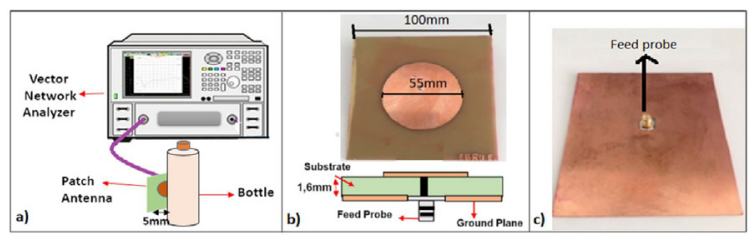

Figure 1. Experimental setup a) The measurement system b) Front view and structure of the antenna c) Back view of the antenna. with oxidising liquids, and their mixing as a result of any impact should be prevented. Because oxidising liquids enter into exothermic reactions with flammable liquids and cause fires and explosions. For this reason, the hazardous liquid recognition system we recommend consists of 3 stages. It makes the S-parameter measurement using a liquid measurement system of unknown type and at the first stage, from this measurement, it decides whether there is a hazardous liquid such as flammable or oxidant in the liquid. It tells you that the liquid is safe if there is no hazardous liquid concentration in the liquid. In step 2, if there is a hazardous liquid concentration in the liquid content, it decides the type of the liquid, i.e. whether it is flammable or oxidant (oxidiser). In the third stage, if the liquid is a flammable liquid, it finds the type of liquid (Methanol, ethanol, 1-propanol and Isopropanol) and \% of the flammable concentration in the liquid. The steps of the algorithm are given in Fig. 2.

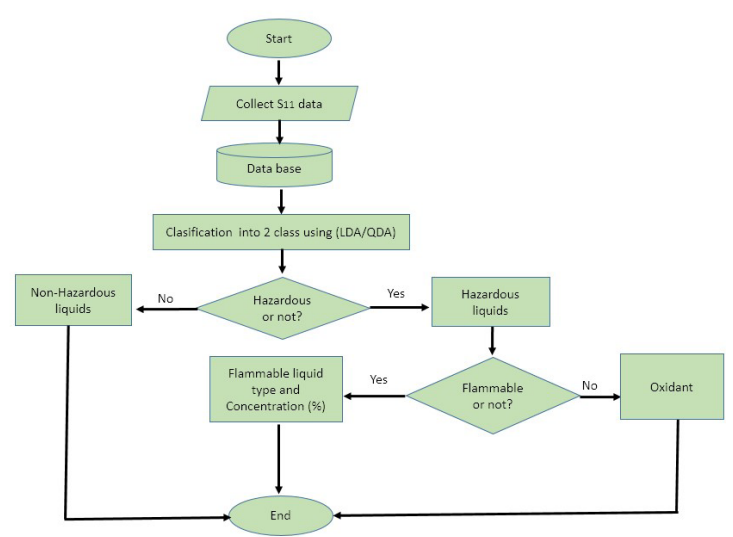

Figure 2. Flowchart of the classification phase

For liquid identification, predictions were made for a total of 49 liquids, 41 hazardous and 8 non-hazardous liquids. In this prediction, 2 different algorithms were used to select the most successful algorithm and the performances of the algorithms were compared. The types of the liquids tested are given in Table 1.

Table 1.Liquid types.

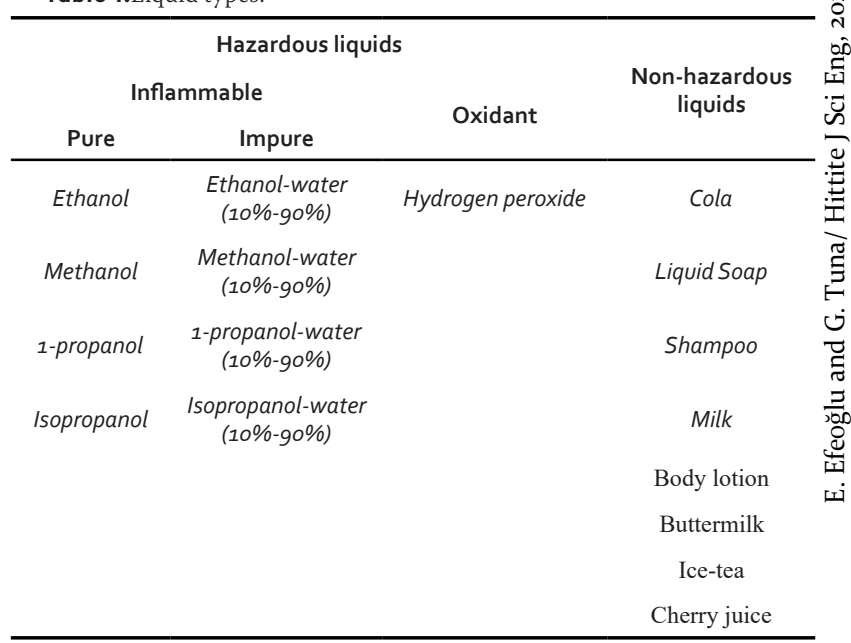



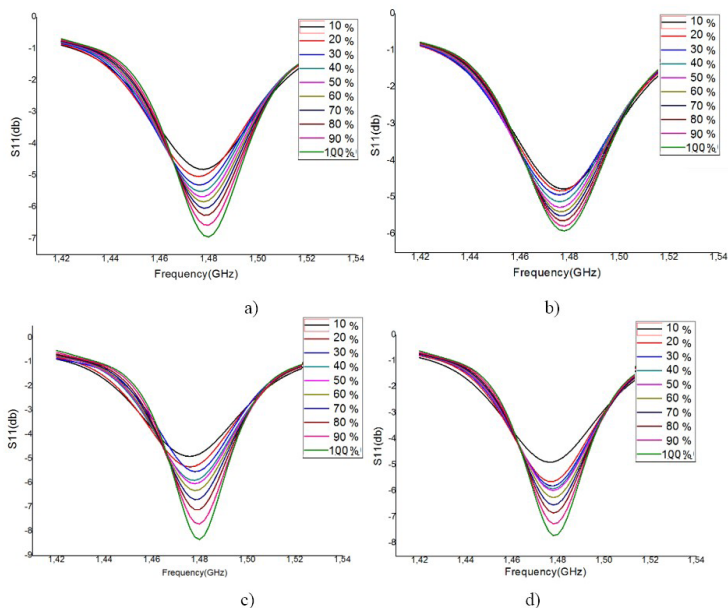

Figure 3. $\mathrm{S}_{11}$ parameters of the water- flammable liquids solutions of different flammable liquid concentrations a) Ethanol b) Methanol c) 1-Propanol, d) Isopropanol.

\section{RESULTS AND DISCUSSION}

The proposed microwave measurement system was used to measure all liquids. S parameter measurement of pure (100\% flammable liquids) and their aqueous solutions containing $10-90 \%$ flammable liquid by volume are given in Fig. 3 and the measurement of other liquids are given in Fig. 4.

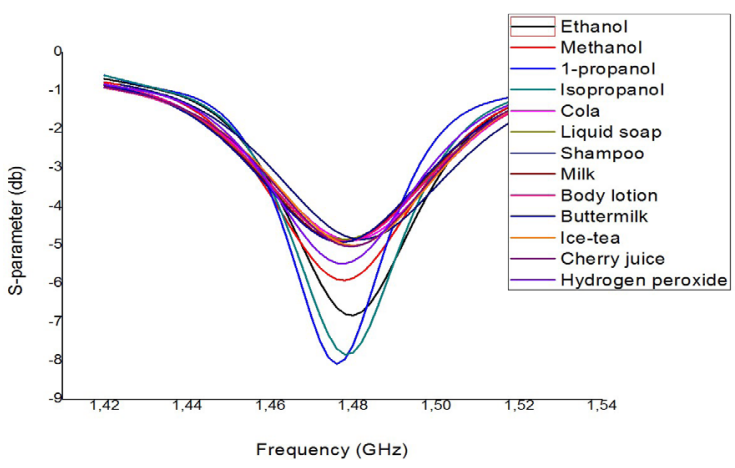

Figure 4. S-parameter measurement of different liquids

\section{Performance Metrics}

There are some performance metrics used to compare the classification performance of algorithms. These metrics indicate which classification algorithm performs better in the given setting. One of the performance metrics used in the study is the accuracy criterion, which gives the total sample rate of correctly classified samples. The accuracy rate of the classification algorithm is calculated using (10).

$$
\text { Accuracy }=\frac{\mathrm{TP}+\mathrm{TN}}{\mathrm{TP}+\mathrm{TN}+\mathrm{FP}+\mathrm{FN}}
$$

where, TP (True positive) is positive test result when actual state is positive, FP (False positive) is positive test result when actual state is negative, TN (True negative) is negative test result when actual state is negative, and FN (False negative) is negative test result when actual state is positive.
Precision and Recall values are also among the performance metrics used and it is accepted that a classifier with high Precision and high Recall values makes a good classification. Precision $(\mathrm{P})$ is the number of TP over the number of TP plus the number of FP (11).

$$
\mathrm{P}=\frac{\mathrm{TP}}{\mathrm{TP}+\mathrm{FP}}
$$

Recall (R) is the number of TPs over the number of TP plus the number of FN (12).

$$
\mathrm{R}=\frac{\mathrm{TP}}{\mathrm{TP}+\mathrm{FN}}
$$

Another commonly used performance metric is Kappa and is calculated using (13). P(a) represents the algorithm's accuracy, $\mathrm{P}(\mathrm{e})$ represents the weighted average of the expected accuracy of the algorithm, which makes random predictions in the same dataset. If a classification is successful, precision and recall values become close to 1 .

$$
\mathrm{K}=\frac{\mathrm{P}(\mathrm{a})-\mathrm{P}(\mathrm{e})}{1-\mathrm{P}(\mathrm{e})}
$$

One of the indicators of how many errors occurred during classification is Root Mean Square Error (RMSE) value and it is calculated using (14).

$$
R M S E=\sqrt{\frac{\left(a_{1}-b_{1}\right)^{2}+\ldots .+\left(a_{n}-b_{1 n}\right)^{2}}{n}}
$$

where a represents the estimated values and b represents the actual values. Confusion matrices are used to measure the success of the algorithm and contain the most descriptive information about the classification results.

\section{Overall Results}

The recall precision, Kappa and RMSE values obtained from the classification made using LDA and QDA are given in Fig. 5(a) and (b) in order to compare their performances. As can be seen in Fig. 5(a) the RMSE of QDA was 0.008 but the RMSE of LDA was 0.075. The low RMSE value indicates that QDA classified with fewer errors. While the accuracy of LDA was $92 \%$, the accuracy of QDA was 98\%. Recall, Precision and Kappa value also indicate the success of QDA. The Precision value of LDA in classifications was 0.97 , the Recall and Kappa values were 0.96 and 0.91 , respectively. The higher of these values (precision 1, recall 0.99 and Kappa 0.99) indicates that 
Table 2.Accuracy of the proposed approach for different liquids

\begin{tabular}{|c|c|c|c|c|c|c|}
\hline & \multirow[b]{2}{*}{ Type of liquids } & \multirow[b]{2}{*}{ Tested liquids } & \multicolumn{2}{|l|}{$\angle D A$} & \multicolumn{2}{|l|}{$Q D A$} \\
\hline & & & $\begin{array}{l}\text { Correctly predicted } \\
\text { liquids }\end{array}$ & $\begin{array}{l}\text { Incorrectly } \\
\text { predicted } \\
\text { liquids }\end{array}$ & $\begin{array}{l}\text { Correctly predicted } \\
\text { liquids }\end{array}$ & $\begin{array}{l}\text { Incorrectly } \\
\text { predicted } \\
\text { liquids }\end{array}$ \\
\hline \multirow{6}{*}{ 1st Step } & $\begin{array}{l}\text { Non-hazardous } \\
\text { liquids }\end{array}$ & $\begin{array}{c}\text { Cola } \\
\text { Soap, } \\
\text { Shampoo } \\
\text { Milk } \\
\text { Body lotion } \\
\text { Buttermilk } \\
\text { Ice-tea (peach) } \\
\text { Cherry juice }\end{array}$ & $\begin{array}{c}\text { Cola } \\
\text { Soap, } \\
\text { Shampoo } \\
\text { Milk } \\
\text { Body lotion } \\
\text { Ice-tea (peach) } \\
\text { Cherry juice }\end{array}$ & Buttermilk & $\begin{array}{c}\text { Cola } \\
\text { Soap, } \\
\text { Shampoo } \\
\text { Milk } \\
\text { Body lotion } \\
\text { Buttermilk } \\
\text { Ice-tea (peach) } \\
\text { Cherry juice }\end{array}$ & $\begin{array}{l}--- \\
--- \\
--- \\
--- \\
--- \\
--- \\
--- \\
---\end{array}$ \\
\hline & \multirow{5}{*}{$\begin{array}{l}\text { Hazardous } \\
\text { Liquids }\end{array}$} & Ethanol & & Ethanol $\% 10$ & Ethanol & --- \\
\hline & & $\begin{array}{c}(10,20,30,40,50,60 \\
70,80,90,100) \%\end{array}$ & $\begin{array}{c}\text { Ethanol } \\
(20,30,40,50,60,70,80,\end{array}$ & $\begin{array}{c}\text { Methanol } \\
\% 10\end{array}$ & $\begin{array}{c}(10,20,30,40,50,60 \\
70,80,90,100) \%\end{array}$ & $-\cdots$ \\
\hline & & $\begin{array}{c}\text { Methanol } \\
(10,20,30,40,50,60 \\
70,80,90,100) \%\end{array}$ & $\begin{array}{c}90,100) \% \\
\text { Methanol } \\
(20,30,40,50,60,70,80, \\
90,100) \%\end{array}$ & & $\begin{array}{c}\text { Methanol } \\
(10,20,30,40,50,60 \\
70,80,90,100) \%\end{array}$ & $\begin{array}{l}--- \\
--- \\
--- \\
---\end{array}$ \\
\hline & & $\begin{array}{c}\text { 1-Propanol } \\
(10,20,30,40,50,60 \\
70,80,90,100) \%\end{array}$ & $\begin{array}{c}\text { 1-Propanol } \\
(10,20,30,40,50,60,70, \\
80,90,100) \% \\
\text { Isopropanol }\end{array}$ & & $\begin{array}{c}1 \text {-Propanol } \\
(10,20,30,40,50,60 \\
70,80,90,100) \%\end{array}$ & $\begin{array}{l}--- \\
--- \\
--- \\
---\end{array}$ \\
\hline & & $\begin{array}{c}\text { Isopropanol } \\
(10,20,30,50,60,70 \\
80,90,100) \%\end{array}$ & $\begin{array}{c}(10,20,30,40,50,60,70 \\
80,90,100) \%\end{array}$ & & $\begin{array}{c}\text { Isopropanol } \\
(10,20,30,50,60,70 \\
80,90,100) \%\end{array}$ & $\begin{array}{l}--- \\
\cdots-- \\
---\end{array}$ \\
\hline \multirow[t]{2}{*}{ 2nd Step } & Oxidising liquid & Hydrogen peroxide & Hydrogen peroxide & --- & Hydrogen peroxide & -- \\
\hline & \multirow{4}{*}{$\begin{array}{c}\text { Detect flammable } \\
\text { liquids } \\
\text { concentration }\end{array}$} & $\begin{array}{c}\text { Ethanol } \\
(10,20,30,40,50,60 \\
70,80,90,100) \%\end{array}$ & $\begin{array}{c}\text { Ethanol } \\
(10,20,30,40,50,60 \\
70,80,90,100) \%\end{array}$ & & $\begin{array}{c}\text { Ethanol } \\
(10,20,30,40,50,60 \\
70,80,90,100) \%\end{array}$ & $\begin{array}{l}\cdots-- \\
\cdots-- \\
\cdots--\end{array}$ \\
\hline \multirow{3}{*}{ 3rd Step } & & $\begin{array}{c}\text { Methanol } \\
(10,20,30,40,50,60 \\
70,80,90,100) \%\end{array}$ & $\begin{array}{c}\text { Methanol } \\
(10,20,30,40,50,60 \\
70,80,90,100) \%\end{array}$ & & $\begin{array}{c}\text { Methanol } \\
(10,20,30,40,50,60 \\
70,80,90,100) \%\end{array}$ & $\begin{array}{l}--- \\
--- \\
--- \\
---\end{array}$ \\
\hline & & $\begin{array}{c}\text { 1-Propanol } \\
(10,20,30,40,50,60 \\
70,80,90,100) \%\end{array}$ & $\begin{array}{c}\text { 1-Propanol } \\
(10,20,30,40,50,60 \\
70,80,90,100) \%\end{array}$ & & $\begin{array}{c}\text { 1-Propanol } \\
(10,20,30,40,50,60 \\
70,80,90,100) \%\end{array}$ & $\begin{array}{l}--- \\
-\cdots \\
--- \\
---\end{array}$ \\
\hline & & $\begin{array}{c}\text { Isopropanol } \\
(10,20,30,50,60,70, \\
80,90,100) \%\end{array}$ & $\begin{array}{c}\text { Isopropanol } \\
(10,20,30,50,60,70, \\
80,90,100) \%\end{array}$ & $\begin{array}{c}\text { Isopropanol } \\
40 \%\end{array}$ & $\begin{array}{c}\text { Isopropanol } \\
(10,20,30,50,60,70, \\
80,90,100) \%\end{array}$ & $\begin{array}{l}\text { Isopropanol } \\
40 \%\end{array}$ \\
\hline
\end{tabular}

QDA was more successful.

Information including all liquid recognition experiments and techniques used are given in Table 2. In liquid recognition, the LDA algorithm predicted that buttermilk, which is actually a non-hazardous liquid, was a hazardous liquid, and the hazardous liquid 10\% Ethanol and $10 \%$ Methanol aqueous solutions were predicted as nonhazardous liquids. It could not accurately predict a total of 3 types of liquids. While the algorithm was estimating the liquid concentration, it predicted the isopropanolwater solution with an isopropanol concentration of $40 \%$ as a hazardous liquid, but could not accurately predict its concentration. It can be seen that QDA correctly predicted all liquid types. On the other hand, although it correctly predicted the type of isopropanol-water solution with an isopropanol concentration of $40 \%$, it could not predict the concentration correctly.

\section{CONCLUSION}

Fire safety and liquid controls play a key role in preventing loss of life and property that may occur as a result of terrorist attacks and sabotage. In this study, a system for liquid classification using S-parameter measurements and discriminant analysis of liquids in the microwave frequency band is proposed. The false alarm rate of the system is very low, it is a system with a high accuracy rate and can detect even a hazardous liquid with a concentration of $10 \%$ in its content. Another advantage of this proposed system is that while other systems only detect liquid, this system can determine both the type of hazardous liquid and the proportion of the hazardous liquid concentration in the liquid. Moreover, this quick identification system is cheaper than other systems. LDA and QDA algorithms were used to select the best algorithm for liquid recognition on the data set obtai- 


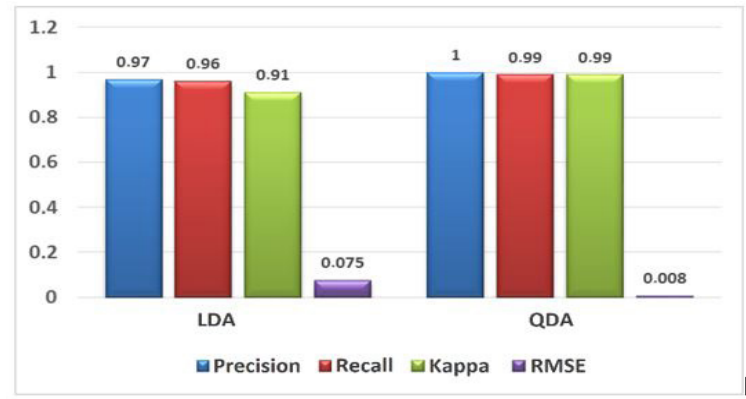

(a)

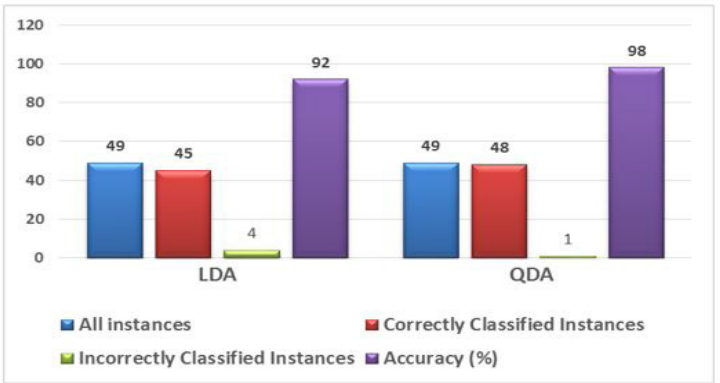

(b)

Figure 5. Performance metrics of LDA and QDA algorithms (a) Accuracy related metrics, (b) accuracy rate of LDA and QDA.

ned from microwave measurements and the performances of these algorithms were compared. The results show that QDA can detect liquids with lower RMSE values and higher accuracy rates compared to LDA. A prototype system that integrates the overall process proposed in this study and the experimental setup and uses QDA for liquid classification is under development. After a group of field tests, it can be used for liquid classification at security checkpoints.

\section{CONFLICT OF INTEREST}

Authors approve that to the best of their knowledge, there is not any conflict of interest or common interest with an institution/organization or a person that may affect the review process of the paper.

\section{AUTHOR CONTRIBUTION}

All the work in this study were performed equally by the authors.

\section{REFERENCES}

1. Prugh, R.W. Life-safety concerns in chemical plants. Process Safety Progress. 35(1) (2016) 18-25.

2. Cox, B.L., Carpenter, A.R., Ogle, R.A. Lessons learned from case studies of hazardous waste/chemical reactivity incidents. Process Safety Progress. 33(4) (2014) 395-98.

3. Morrison, D.T., Stern, M., Osorio-Amado, C.H. Waste solvents to trash haulers: lessons learned from hazardous waste accidents. Process safety progress. 37(3) (2018) 427-41.

4. Ness, A., Gibson, R. Handling chemicals in small containers. Process safety progress. 24(4) (2005) 299-302.

5. Alexeev, S., Smirnov, V., Barbin, N., Alexeeva, D.Y. Evolution of the classification of flammable and combustible liquids in Russia. Process safety progress.37(2) (2018) 230-36.

6. DaCunha, S., Gerbaud, V., Shcherbakova, N., Liaw, H.J. Classification for ternary flash point mixtures diagrams regarding miscible flammable compounds. Fluid Phase Equilibria. 466 (2018) 110-23.

7. Stefanidou, M., Athanaselis, S., Spiliopoulou, C. Health impacts of fire smoke inhalation. Inhalation toxicology. 20(8) (2008) 761-66.

8. Purser, D.A., McAllister, J.L. Assessment of hazards to occupants from smoke, toxic gases, and heat. SFPE handbook of fire protection engineering. Springer; 2016. p. 2308-428.

9. Yuan, S., Zhang, Z., Sun, Y., Kwon, JS-I., Mashuga, C.V. Liquid flammability ratings predicted by machine learning considering aerosolization. Journal of hazardous materials. 386 (2020) 121640.

10. Yuan, W., Lv, W., Wang, H., Ma, Li, S. H. Performance prediction of suspension freeze crystallization for the treatment of liquid hazardous wastes via machine learning methods, Journal of Cleaner Production, (2021) 129629.

11. Yuan, Ji, C., Jiao, S., Huffman, Z., El-Halwagi, M., Wang, M.M., Q., Predicting flammability-leading properties for liquid aerosol safety via machine learning, Process Safety and Environmental Protection, 148 (2021) 1357-1366.

12. Jiao, Z., Ji, C., Yuan, S., Zhang, Z., Wang, Q. Development of machine learning based prediction models for hazardous properties of chemical mixtures, Journal of Loss Prevention in the Process Industries, 67 (2020) 104226.

13. Zhang, Z., Yuan, S., Yu, M., Mannan, M.S., Wang, Q., A hazard index for chemical logistic warehouses with modified flammability rating by machine learning methods, ACS Chemical Health \& Safety, 27 (2020) 190-197.

14. Mahmodi, K., Mostafaei, M., Mirzaee-Ghaleh, E. Detection and classification of diesel-biodiesel blends by LDA, QDA and SVM approaches using an electronic nose. Fuel. 258 (2019) 116114.

15. Ji, C., Jiao, Z., Yuan, S., El-Halwagi, M.M., Wang, Q., Development of novel combustion risk index for flammable liquids based on unsupervised clustering algorithms, Journal of Loss Prevention in the Process Industries, 70 (2021) 104422

16. Li, Z., Haigh, A., Soutis, C., Gibson, A., Sloan, R. Microwaves sensor for wind turbine blade inspection. Applied Composite Materials. 24(2) (2017) 495-512.

17. Borisov, V., Karpenko, A. Using of the Michelson microwave interferometer for the measurement of permittivity of thin-layer materials. Russian journal of nondestructive testing. 37(8) (2001) 597-99.

18. Yurchenko, A.V., Novikov, A., Kitaeva, M.V. A resonator microwave sensor for measuring the parameters of Solar-quality silicon. Russian Journal of Nondestructive Testing. 48(2) (2012) 109-14.

19. Mathur, P., Thakur, A., Kurup, D.G. An artificial neural networkbased non-destructive microwave technique for monitoring fluoride contamination in water. Journal of Electromagnetic Waves and Applications. 34(5) (2020) 612-22.

20. Turgul, V., Kale, I. Permittivity extraction of glucose solutions through artificial neural networks and non-invasive microwave glucose sensing. Sensors and Actuators A: Physical. 277 (2018) 6572 .

21. Sulaiman, N., Srisatit, S. Development of x-ray imaging technique for liquid screening at airport. AIP Conference Proceedings: AIP Publishing LLC; 2016. p. 030006.

22. Orachorn, P., Chankow, N., Srisatit, S. An Alternative Method for Screening Liquid in Bottles at Airports Using Low Energy X-ray Transmission Technique. Radiation environment and medicine: covering a broad scope of topics relevant to environmental and 
medical radiation research. 8(2) (2019) 77-84.

23. Chen, H., Hu, Z., Wang, P., Xu, W., Hou Y. Application of spectral droplet analysis method in flammable liquids identification. Paper presented at 2019 International Conference on Optical Instruments and Technology: Optical Sensors and Applications: International Society for Optics and Photonics, pp. 1143609, 2020.
24. Sun, L. Liquid dangerous goods detection based on electronic nose odor recognition technology. Paper presented at International Symposium on Photoelectronic Detection and Imaging 2013: Infrared Imaging and Applications: International Society for Optics and Photonics, pp. 890721, 2013. 